\title{
Análisis de la conciliación extrajudicial civil en la Costa Atlántica colombiana
}

\section{Analysis of civil extrajudicial conciliation in the Colombian Atlantic Coast}

\author{
DOI: http://dx.doi.org/10.17981/juridcuc.14.1.2018.9
}

Artículo de investigación. Fecha de recepción: 07/06/2018 Fecha de aceptación: 23/08/2018

\author{
Abel Meza Godoy \\ Universidad de la Costa (Colombia) \\ ameza24@cuc.edu.co \\ Milton Arrieta López iD
Universidad de la Costa (Colombia) \\ marrieta7@cuc.edu.co \\ Sara Noli \\ Universidad del Norte (Colombia) \\ saranoli@hotmail.it
}

Para citar este artículo:

Meza, A., Arrieta, M. y Noil S. (2018). Análisis de la conciliación extrajudicial civil en la Costa Atlántica colombiana. JURÍDICAS CUC, vol. 14, no. 1, pp. 187-210. DOI: http://dx.doi.org/10.17981/ juridcuc.14.1.2018.9

\section{Resumen}

La conciliación como método alternativo de solución de conflictos fue concebida como una oportunidad cierta y adecuada para que los sujetos de derecho solucionaran sus conflictos de manera pacífica y concertada con la presencia de un tercero imparcial sin poder de decisión, pero con atribuciones que encausan y procuran de manera asertiva la negociación. Desde su implementación como requisito de procedibilidad, se plantea el objetivo de discutir si se puede comprender la conciliación como una oportunidad de amparo de la tutela judicial efectiva o como una simple exigencia de ley. En ese sentido, y a partir de las estadísticas del SICAAC en la Costa Atlántica, se concluye que aún la sociedad no interioriza de manera suficiente los beneficios de este medio de solución de conflictos autocompositivo. La metodología utilizada es la revisión documental, bibliográfica y el análisis crítico al consultar, revisar y analizar la doctrina, jurisprudencia e información documental originada por el Ministerio de Justicia. Palabras clave: conciliación, SICCAC, requisito de procedibilidad, método autocompositivo, método alternativo, MASC

\section{Abstract}

The conciliation as an alternative conflict resolution method was conceived as a positive opportunity for parties to settle their conflicts in a peaceful and concerted manner with the presence of an impartial third party without decision-making power, but with attributions to address and assertively seek an agreement which will be stated in a conciliation act. However, since the implementation as a procedural requirement, the objective is to discuss if conciliation can be understood as a certain opportunity to protect effective judicial protection or as a simple procedure derived from the law. Based on the statistics of SICAAC on the Atlantic Coast, we can conclude that the benefits of conciliation as an alternative dispute resolution method have not yet been sufficiently internalized by society. The methodology used is the documentary, bibliographic and critical analysis review, when consulting, reviewing and analyzing doctrine, jurisprudence and documentary information originated by the Ministry of Justice.

Keywords: conciliation, SICCAC, procedural requirement, consensual process, mediation, ADR 


\section{INTRODUCCIÓN}

La Constitución Política de Colombia protegió el acceso a la justicia como un derecho de las personas dentro de la función jurisdiccional del Estado en sus artículos 228 y 229. Esta función no es exclusiva de los jueces de la República, tal como lo mencionó la Corte Constitucional en sentencia C-1195 de 2001, al manifestar lo siguiente:

Según la jurisprudencia de esta Corporación, el derecho a acceder a la justicia tiene un significado múltiple. Entre otros, comprende contar con procedimientos idóneos y efectivos para la determinación legal de derechos y obligaciones, que las controversias planteadas sean resueltas dentro de un término prudencial y sin dilaciones injustificadas, que las decisiones sean adoptadas con el pleno respeto del debido proceso, que exista un conjunto amplio y suficiente de mecanismos para el arreglo de controversias, que se prevean mecanismos para facilitar el acceso a la justicia por parte de los pobres, que la oferta de justicia permita el acceso a ella en todo el territorio nacional. Este derecho se garantiza también a través del uso de mecanismos alternativos de resolución de conflicto (Corte Constitucional. Sala Plena, C-1195/01, 2001).

La posibilidad de acceso a la justicia a través de los particulares se encuentra amparada en el artículo 116 de la Constitución Política de Colombia al otorgarles investidura transitoria de jurisdicción, en la condición de conciliadores o en la de árbitros habilitados por las partes con el objetivo de conferir los mismos efectos de una decisión judicial a través de una sentencia al acta de conciliación o al laudo arbitral proferido por un Tribunal de Arbitramento. No en vano la Corte Constitucional ha manifestado que:

(...) de conformidad con la jurisprudencia de la Corte, el acceso a la justicia comporta no sólo la posibilidad de que cualquier persona solicite la protección de sus derechos ante los jueces competentes, sino también, por expresa autorización del artículo 116 constitucional, que pueda resolver sus disputas a través de mecanismos como la conciliación o el arbitraje (Corte Constitucional. Sala Plena, C-314/02, 2002). 
La investidura jurisdiccional para conciliadores y árbitros es transitoria y para efectos de la conciliación, el ungido con tal prerrogativa debe prever su responsabilidad, no para proferir una providencia que resuelva la litis, sino para proveer herramientas a las partes en conflicto, que en su autonomía buscarán una solución pacífica a la circunstancia problemática. Por el establecimiento de la conciliación como un requisito de procedibilidad, se presenta la disyuntiva sobre la perspectiva del ciudadano en cuanto a si es entendida como una oportunidad de solución pacífica de controversias o simplemente como una etapa más de los procesos judiciales, más aún cuando se configura el hecho notorio por el cual los ciudadanos confunden la convocatoria para comparecer a la audiencia de conciliación con la notificación de demanda judicial en contra a sus intereses, cuando en realidad la conciliación debe entenderse como una oportunidad, no solo para lograr la descongestión judicial, sino también para solucionar un conflicto existente de manera más satisfactoria.

No está de más resaltar las críticas hacia la institución jurídica de la conciliación como requisito de procedibilidad necesario para que la parte interesada pueda acceder a los jueces de la República para que decidan su petitorio al entenderse tal requisito como una desnaturalización del fin mismo de la conciliación (Maldonado y Montaña, 2017, p. 123), no obstante, este hecho lleva implícita la intención de otorgar la oportunidad para que el conflicto pueda solucionarse entre los directamente legitimados e interesados y no por un tercero ajeno a ella.

\section{Desarrollo}

La historia de la conciliación en Colombia encuentra sus inicios en el derecho laboral, más específicamente en el decreto 2158 de 1948, que fue tomado como norma permanente por el decreto 4133 de 1948: el Código Procesal del Trabajo, que permitía, en su artículo 19, la conciliación en cualquier tiempo, antes o después de presentarse la demanda. La ley 23 de 1991 quiso regular lo referente a la legislación laboral, no obstante, esta legislación nunca entró en vigor, en tanto que no se expidió el 
decreto que permitía realizar las modificaciones al Ministerio del Trabajo y Seguridad Social para la ejecución debida.

El artículo 31 del decreto 2303 de 1989, haciendo relación a la materia agraria, dispuso que en los procesos ordinarios, y en especial de deslinde y amojonamiento, hubiese lugar a una audiencia preliminar de conciliación al igual que en todos los procesos declarativos de índole agraria, conforme el artículo 35 de la misma norma.

Es importante mencionar el artículo 101 del decreto 2282 (1989) que introdujo la audiencia de conciliación judicial, en donde no solo fue preponderante su celebración en los procesos ordinarios, sino que incluía consecuencias por la inasistencia de las partes, como el indicio grave en contra de las pretensiones o de las excepciones de mérito según fuere el caso, como también multas de 5 a 10 salarios mínimos mensuales al renuente.

En materia civil, la ley 446 de 1998, en su artículo 64, definió la conciliación como un mecanismo alternativo de solución de conflictos, resaltando el papel del conciliador como un tercero neutral y calificado, al igual que subraya que la solución del conflicto nace de la gestión de las mismas partes. En particular, la ley 446 de 1998, en el artículo 101, que fue derogada por el artículo 49 de la ley 640 de 2001 (Bermejo, 2015, p. 112), otorgaba la oportunidad de realizar la audiencia de conciliación judicial en los procesos que no se hubiese proferido sentencia de primera o única instancia y que versaren sobre materias susceptibles de conciliación; este hecho no fue ajeno para el proceso ejecutivo, en vista de que se exigía la conciliación cuando en la ejecución se presentaban excepciones de mérito. Cabe mencionar que la diligencia procesal antes mencionada, a su vez, fue derogada por el artículo 69 de la ley 794 de 2003.

González (1999), en la exposición de motivos de la ley 640 de 2001 , resalta la importancia del fortalecimiento de la justicia alternativa que se desarrollaba en la ley 446 de 1998 como forma de resolución pacífica de las controversias al mencionar que permitiría a los colombianos ser "mejores vecinos, más amigos y por ende hombres y mujeres de paz, que sabrán sembrar semillas de esperanza y transitarán caminos de entendimiento" (p. 1); de esta enunciación se puede derivar la exigencia de ley, 
previa a la iniciación de procesos declarativos. En un sentido similar, Castillo (2012) hace dimanar de la conciliación una función ética al considerar que permite la construcción de una cultura de paz.

La ley 1564 de 2012, conocida como el Código General del Proceso, no se desprendió de la importancia de la conciliación extrajudicial al ventilarla como una causal de inadmisión de la demanda, cuya apreciación es diferente a la consagrada por el artículo 36 de la ley 640 de 2001 que la había tipificado como causal de rechazo in limine o de plano; no obstante, al ser el Código General del Proceso norma posterior, es la norma aplicable actualmente como causal de inadmisión, más aún cuando lo que se pretende es la protección al acceso a la justicia en el evento de que el accionante hubiese omitido relacionar o anexar la constancia del agotamiento de este requisito por simple negligencia $\mathrm{u}$ olvido.

Conforme al decreto 979 de 9 de junio de 2017, emanado del Ministerio de Justicia y del Derecho (2017), se adoptó el Plan Decenal del Sistema de Justicia, por medio del cual se instituye la conciliación como un método alternativo de solución de conflictos, concepto que se relaciona con la implementación de la conciliación en los territorios que históricamente han tenido presencia de los actores del conflicto colombiano.

\section{La conciliación en civil como método autocompositivo de resolución de conflictos}

La Constitución Política de Colombia (1991), en su artículo 116, permitió que los particulares estuviesen investidos de jurisdicción de manera transitoria en su calidad de árbitros y conciliadores expresando:

La Corte Constitucional, la Corte Suprema de Justicia, el Consejo de Estado, el Consejo Superior de la Judicatura, la Fiscalía General de la Nación, los Tribunales y los Jueces, administran justicia. También lo hace la justicia penal militar (Art. 116).

Por su parte, el Congreso ejercerá determinadas funciones judiciales. 
Excepcionalmente, la ley podrá atribuir función jurisdiccional en materias precisas a determinadas autoridades administrativas. Sin embargo, no les será permitido adelantar la instrucción de sumarios ni juzgar delitos.

Los particulares pueden ser investidos transitoriamente de la función de administrar justicia en la condición de conciliadores o en la de árbitros habilitados por las partes para proferir fallos en derecho o en equidad, en los términos que determine la ley (Const., 1991).

$\mathrm{Al}$ relacionar el contenido del artículo antes expuesto con el derecho constitucional de acceso a la justicia desarrollado en los artículos 228 y 229 , se infiere que el concepto de administración de justicia no queda supeditado a la intervención de los jueces de la República como agentes del Estado, esto es, como representantes de la función jurisdiccional, sino que la justicia también se depreca de los particulares cuando éstos prestan el servicio jurisdiccional transitorio que les faculta para obrar en la conciliación, de manera que las partes en conflicto están facultadas para resolver la controversia de forma consensuada y con el propósito de obtener un arreglo justo. Azula (2016) afirma en relación con este punto lo siguiente:

El fundamento o la razón que tuvo el legislador para establecer la conciliación es tratar de obtener un arreglo entre las partes para ahorrar el respectivo proceso y evitar, entre otras cosas las consecuencias que una actuación de esta índole implica (p. 433).

En lo referente la Corte Constitucional, en sentencia C-1195 del 15 de noviembre de 2001, el Magistrado Ponente Cepeda Espinoza manifestó:

De conformidad con la jurisprudencia de la Corte, el acceso a la justicia comporta no sólo la posibilidad de que cualquier persona solicite la protección de sus derechos ante los jueces competentes, sino también, por expresa autorización del artículo 116 constitucional, que pueda resolver sus disputas a través de mecanismos como la conciliación o el arbitraje (Corte Constitucional. Sala Plena, C-1195/01, 2001). 
La ley 640 de 2001 condicionó la temporalidad de la investidura de jurisdicción del conciliador hasta un término de tres meses, en efecto hay que entender que el concepto de temporalidad se predica del tiempo máximo otorgado al particular para que pueda realizar actuaciones conforme a la investidura autorizada constitucionalmente, la cual inicia desde el momento de la asignación al particular como conciliador, no pudiendo sobrepasar el término estipulado por ley. Sobre este aspecto la Corte Constitucional mediante la sentencia C-893/01 indica:

Esta facultad es esencialmente ocasional o transitoria y es además de carácter voluntario o espontáneo, por cuanto al tenor de la norma superior en comento son las partes quienes habilitan al particular para resolver su controversia. La transitoriedad y alternatividad de estos instrumentos deriva del hecho de que constituyen una forma de colaboración de los particulares para el buen suceso de la administración de justicia (Corte Constitucional, Sala Plena, C-893/01, 2001).

En alusión al acuerdo de las partes y trayendo a colación la clasificación de las fuentes de las obligaciones, específicamente las mencionadas por Tamayo (2004): "la mayor parte de los códigos de países de América Latina, debido a la influencia del código francés, han adoptado la clasificación clásica: contratos, cuasicontratos, delitos, cuasidelitos y ley" (p. 32).

Con respecto a lo anterior, las prestaciones que de común acuerdo se ventilan en un acta de conciliación provienen de una fuente consensual de obligaciones amparada en la ley y en la Constitución Política de Colombia, por lo tanto, el acta de conciliación presta mérito ejecutivo y hace tránsito a cosa juzgada. No está de más subrayar que los poderes jurisdiccionales de decisión y de coerción que invisten a los jueces de la República no los posee el conciliador, toda vez que éste último es un tercero imparcial que media por el consenso entre las partes, quedando para el conciliador vedada la posibilidad de proferir providencias que pongan fin a controversias litigiosas emanadas de pretensiones declarativas, constitutivas o de condena, sin embargo, el conciliador se encuentra investido con el poder jurisdiccional de convalidación, el cual ejerce una vez el asunto litigioso haya sido 
discutido en la audiencia y, en consecuencia, se materialice un acuerdo entre las partes.

\section{La conciliación como mecanismo de solución de conflictos}

La ley 446 de 1998, en su artículo 64, definió la conciliación de la siguiente manera "La conciliación es un mecanismo de resolución de conflictos a través del cual, dos o más personas gestionan por sí mismas la solución de sus diferencias, con la ayuda de un tercero neutral y calificado, denominado conciliador". Por otro lado, la Corte Constitucional, en sentencia C-1195 del 15 de noviembre de 2001, en desarrollo del concepto de conciliación manifestó que:

El término conciliación tiene dos sentidos distintos según el contexto en que es utilizado: uno procedimental y otro sustancial. En relación con su acepción procedimental, la conciliación es "un mecanismo de resolución de conflictos a través del cual, dos o más personas gestionan por sí mismas la solución de sus diferencias, con la ayuda de un tercero neutral y calificado, denominado conciliador. (Corte Constitucional. Sala Plena, C-1195/01, 2001).

Según la definición mencionada y de acuerdo con el Concepto técnico 3970 del Ministerio del Trabajo (2018), la conciliación instituye una sucesión de fases predispuestas que tiene por objeto eventual, pero no obligatorio, un acuerdo entre dos o más personas. Empero, la palabra conciliación se refiere asimismo al "acuerdo al que se llega mediante la celebración del procedimiento conciliatorio. En este segundo sentido sustancial, la conciliación se materializa en un acta que consigna el acuerdo al que llegan las partes, certificado por el conciliador" (Ministerio del Trabajo de Colombia, 2018).

Azula (2016) definió a la conciliación de la siguiente manera:

Tratando de dar un concepto amplio de la conciliación, podemos decir que es un acto efectuado por las partes o presuntas partes, con intervención de un funcionario, en virtud del cual, mediante acuerdo total o parcial de lo que se controvierte, se le pone fin a un proceso o se evita uno futuro (p. 429). 


\section{Para Cuesta-Cuesta (2015), la conciliación es:}

(...) una figura con rango constitucional y legal mediante la cual las partes, con la colaboración de un tercero imparcial y neutral denominado conciliador, buscan la solución de un conflicto que es desistible, transigible, y no está prohibido por la ley llevar a cabo la realización de dicho trámite. Tiene como efectos que presta mérito ejecutivo, hace tránsito a cosa juzgada y suspende el término de prescripción y caducidad (p. 16).

Tamez, Montalvo, Leyva y Hernández (2018), por su parte, especifican que "los conciliadores no interpretan el derecho ni las normas, sino que les corresponde ponderar y equilibrar los intereses contrapuestos de las partes, lo que hace que sus resultados no tengan el carácter decisivo de una sentencia" (p. 391).

Arboleda, Ramírez, Mancipe, Garcés y Arboleda (2018) aclaran sobre la función ética lo siguiente:

La conciliación no es una forma de descongestionar la justicia, dado que su importancia es mucho más amplia que solo ser un medio de descongestión, pues genera tejido social, diálogo y el posicionamiento de los acuerdos como la manera inteligente de resolver los conflictos. Por esto, la conciliación es una nueva forma de hacer justicia (en tanto es un mecanismo alternativo de solución de conflictos) (p. 375-376).

Se considera entonces que la conciliación, más que un método alternativo y/o complementario de solución de conflictos, es un método de autocomposición de controversias; más que una actividad preventiva o resolutiva de la acción judicial iniciada o por iniciar, promueve la convivencia pacífica y el orden justo al propiciar un acuerdo negociado entre las partes sobre asuntos de controversias transigibles, desistibles y conciliables, con la intervención de un tercero imparcial denominado conciliador, quien está investido de jurisdicción de manera transitoria.

\section{Características de la conciliación}

La sentencia de la Corte Constitucional C-893 del 22 de agosto de 2001 desarrolló las características de la conciliación, que se enuncian a partir de las siguientes consideraciones: 
La conciliación es un mecanismo de acceso a la administración de justicia. Como se ha mencionado anteriormente, en los artículos 116, 228 y 229 de la Constitución Política de Colombia, no se limita el acceso a la administración de justicia a los jueces singulares o plurales, siempre que se reviste con jurisdicción de manera transitoria a los particulares como conciliadores y árbitros.

La conciliación es un mecanismo alternativo de solución de conflictos que puede realizarse por fuera del proceso judicial o en el curso del mismo. El artículo 3 de la ley 640 de 2001 expresa la clasificación de la conciliación en derecho y en equidad; igualmente, desde el propio contexto surge la clasificación en judicial y extrajudicial. En ese sentido, se desarrollarán a continuación cada uno de esos conceptos expresados.

Conciliación judicial. Es la que se realiza durante el proceso judicial, la cual se encuentra de manera explícita en la audiencia inicial del proceso verbal o en la audiencia única del proceso verbal sumario, también puede ser solicitada por las partes en el proceso o impulsada por el juez de conocimiento cuando observe asomos de la intención de las partes de llegar a un acuerdo. En este último caso, el juez de conocimiento la podrá impulsar soportado en el artículo 43 de la ley 640 de 2001, que permite realizar la audiencia en cualquier etapa del proceso.

Conciliación extrajudicial. Es la que se realiza fuera del proceso, siempre que se haga conforme a los lineamientos expresados en la ley 640 de 2001 y ante un conciliador habilitado para el efecto. Rojas (2013), la definió así:

En estricto sentido debe entenderse por conciliación extraprocesal aquella que tiene lugar fuera del proceso judicial, sea que se realice ante un juez que haga las veces de conciliador o ante otra autoridad pública o privada, autorizada por ley (p. 243).

Conciliación en derecho y en equidad. Haciendo alusión al concepto de conciliación en equidad, Pallares (2003) manifiesta: 
Se entiende como el modo de dictar las sentencias judiciales o de tomar decisiones administrativas, que toman en cuenta las características de cada caso en particular, de suerte que pueda aplicarse con justicia la ley, redactada en términos abstractos y generales o evaluar un suceso de manera tal que se restaure el equilibrio perdido (p. 119).

En otro de sus apartes aduce que:

En efecto, en un sentido amplio, la equidad se entiende como aplicación de lo justo en una situación particular, o sea al caso concreto. La aplicación de la justicia no es, de otra parte, patrimonio exclusivo de los abogados sino de todos los individuos, dotados como están de facultades intelectuales y morales que permiten discernir entre lo que es justo e injusto cuando se enfrenta a una situación determinada (p. 120).

Respecto a la diferencia entre la conciliación en derecho y la conciliación en equidad, Pallares (2003) manifiesta que:

(...) de alguna forma la diferencia se reduce a la técnica, en el derecho generalizadora y en la equidad concretizadora, en el momento de la aplicación, porque con frecuencia el primero requiere para la solución, el empleo de criterios de equidad, al par que esta última, para no incurrir en la arbitrariedad, saca provecho de técnicas estrictamente jurídicas (p. 130).

Por su parte, Azula (2016) explica la diferencia entre la conciliación en derecho y la conciliación en equidad de la siguiente forma:

Es en derecho cuando el acuerdo se funda en lo que al respecto consagre el ordenamiento positivo. b) Es en equidad si el convenio se obtiene prescindiendo de lo que consagre la norma sobre el punto materia de la disputa o diferencia y se funda en la conciencia (p. 434).

No está de más subrayar que la justicia en equidad no debe operar en contra del orden público ni de las buenas costumbres, de manera que la conciliación en equidad no puede deducirse de un acuerdo arbitrario e ilegal. Con todo, sí se da un sentido de amplitud, en tanto que se busca restablecer el orden justo en- 
tre las partes sin implicar una concreta aplicación de la norma jurídica, como sí se espera de la conciliación en derecho, y para el efecto, se exige que el conciliador sea un abogado calificado para conciliar.

La ley 446 de 1998, desde el artículo 106 hasta el artículo 110, desarrolla aspectos referentes a la conciliación en equidad, de los cuales se destaca el mencionado en el artículo 109 en cuanto a que se otorgan a las actas de conciliación en equidad los mismos efectos de las actas de conciliación en derecho: prestar mérito ejecutivo y hacer tránsito a cosa juzgada. El artículo $3^{\circ}$ de la ley 640 de 2001 exige que la conciliación en derecho se haga ante los centros de conciliación o ante autoridades en cumplimiento de las funciones conciliadoras, mientras que la conciliación en equidad se hace ante conciliadores en equidad, por lo cual se concluye que en ambos casos se podrá agotar el requisito de procedibilidad que expresa el artículo 35 y 38 de la ley 640 de 2001.

Es una forma de resolver conflictos mediante la intervención de un tercero. El tercero del que se hace mención es el conciliador que actúa como mediador imparcial, que vela, además, por que las partes puedan solucionar su conflicto de manera pacífica haciendo propuestas sobre posibles arreglos.

La función del conciliador es la de administrar justicia de manera transitoria. La transitoriedad se predica del término de tres meses que establece el artículo 20 de la ley 640 de 2001, que se constituye para la audiencia de conciliación extrajudicial, sin embargo, la conciliación judicial se impulsa por intermedio del juez de conocimiento en cualquier etapa del proceso antes de dictar sentencia cuando estima que entre las partes existe ánimo de acuerdo.

Es un acto jurisdiccional. Es de recordar en este punto la importancia del efecto de las actas de conciliación, las cuales prestan mérito ejecutivo y hacen tránsito a cosa juzgada, es decir, tienen los mismos efectos de la sentencia en firme.

La conciliación es un mecanismo excepcional. Se presentan casos en los que no es necesario el agotamiento del requisito de procedibilidad que constan en los artículos 35 y 36 de la ley 640 de 2001 (Arrieta y Rojas, 2002), los cuales se determinan a continuación: 
a. Cuando bajo la gravedad del juramento, que se entiende prestado con la presentación de la demanda, se manifieste que se ignora el domicilio, el lugar de habitación y el lugar de trabajo del demandado, o que éste se encuentra ausente y no se conoce su paradero.

b. Cuando en el proceso se pretenda solicitar el decreto y la práctica de medidas cautelares, se puede acudir directamente a la jurisdicción ordinaria.

c. En los procesos de expropiación y los divisorios.

d. En procesos con pretensiones ejecutivas o liquidatarios.

e. En los procesos de familia cuando existan circunstancias de violencia intrafamiliar: esta causal la expuso la sentencia C-1195 de 2001 de la Corte Constitucional amparada en el concepto de protección a la víctima a fin de no obligarla a encontrarse nuevamente con su agresor, al respecto la Corte manifestó:

Para la Corte la obligatoriedad de la conciliación prejudicial como requisito de procedibilidad, resulta no sólo adecuada para alcanzar los fines señalados, sino efectivamente conducente para el logro de éstos, salvo en el caso de la conciliación en asuntos de familia cuando existen condiciones de violencia intrafamiliar. Por esta razón, en materia de familia, la constitucionalidad de este medio depende de que no se hayan presentado situaciones de violencia intrafamiliar, pues en esos eventos no resulta adecuado ni efectivamente conducente que se obligue a la víctima a encontrarse con su agresor. Por ello, la exequibilidad de la norma será condicionada a que cuando hubiere violencia intrafamiliar, la víctima no esté obligada asistir a la audiencia de conciliación y que pueda manifestar tal circunstancia ante el juez competente, si opta por acudir directamente a la jurisdicción del Estado (Corte Constitucional. Sala Plena, C-1195/01, 2001).

f. En los demás casos que determine la ley, como por ejemplo, el existente en el proceso de restitución de tenencia.

Respecto al literal referente a la solicitud de medidas cautelares, es menester aclarar que se excluye el requisito de procedibilidad cuando se hace la mera solicitud, de manera que es innecesaria la práctica de las medidas para que se prescinda del 
mencionado requisito; por consiguiente, si se solicita la medida y por algún motivo ésta no llega a ser decretada, el proceso no entraría en una causal de nulidad por violación del debido proceso.

Aun así, y para efectos de cerrar este aparte, es importante resaltar la relevancia del papel de la conciliación como mecanismo de solución pacífico y autocompositivo, por cuanto el solo hecho de que para un asunto no deba cumplirse el requisito de procedibilidad, no significa que no pueda accionarse la conciliación. Un ejemplo de ello se da en el proceso de restitución de inmueble arrendado en el que expresamente la norma del Código General del Proceso exime el agotamiento de esta exigencia para la presentación de la demanda, pero si se trae a colación el artículo 69 de la Ley 446 de 1998, se observa que si se llegase a lograr un acuerdo de entrega en una audiencia de conciliación donde se discuta la restitución del bien objeto de tenencia y el arrendatario se abstiene de entregar dicho bien en las condiciones de modo, tiempo y lugar pactados en el acta, el director del centro de conciliación puede comisionar a los inspectores de policía para realizar la diligencia de restitución. Dicho de otra manera, si la pretensión es solo la restitución, un simple acuerdo evitaría el desgaste que supone el trámite ante las autoridades judiciales para conseguir el mismo fin previsto procesalmente, además de eximirlo de mayores costos derivados de las expensas de una acción judicial.

Por definición la conciliación es un sistema voluntario, privado y bilateral de resolución de conflictos. En este aparte es importante comprender que las prestaciones que emanan del acuerdo de conciliación poseen una fuente consensual y legal no vinculada al conciliador, estando este último limitado a proponer posibles soluciones de arreglo y suscribir el aval sobre lo consensuado por las partes, que, una vez plasmado en un acta, prestará mérito ejecutivo y dará tránsito a cosa juzgada material o formal, dependiendo del caso conciliable. Así, el conciliador propenderá por que lo acordado posea circunstancias diáfanas de modo, tiempo y lugar para efectos de que, en un eventual incumplimiento, el acta preste el mérito ejecutivo al contener los requisitos del artículo 422 del CGP, es decir, consistir en un título claro, expreso y exigible, y, por consiguiente, el acreedor del derecho solo necesite iniciar la acción ejecutiva pertinente. 
Control, inspección y vigilancia y la creación del SICAAC

El Ministerio de Justicia y del Derecho posee funciones de control, inspección y vigilancia sobre los centros de conciliación y/o arbitraje. Adicionalmente, el Ministerio de Justicia y del Derecho tiene la potestad de imponer las sanciones a que se refiere el artículo 94 de la ley 446 de 1998, como la amonestación escrita, la multa hasta de 200 salarios mínimos legales mensuales vigentes a favor del Tesoro Público, la suspensión de funcionamiento hasta por un término de seis (6) meses y la revocatoria de la autorización de funcionamiento dependiendo de la gravedad de la infracción. De acuerdo con esto y apegado a las nuevas tecnologías en un mundo cada vez más globalizado y comunicado por las redes, el Ministerio creó, mediante resolución 0018 de 18 de enero de 2015, el SICAAC: Sistema de Información de Conciliación, el Arbitraje y la Amigable Composición. De esta manera, el SICAAC fue dispuesto como una herramienta para ejercer control, inspección y vigilancia de los Centros de Conciliación y Arbitraje, teniendo dentro de sus herramientas el registro de la información de las solicitudes, casos y demás trámites derivados de los mismos.

Los centros de conciliación, conciliadores, entidades, o servidores o funcionarios autorizados tienen el deber de registrar las actas de conciliación pertinentes con acuerdo total o parcial, o las constancias de que trata la ley 640 de 2001, lo cual permite tener una base de datos centralizada de las gestiones desarrolladas por estos centros, sus estadísticas de realización de audiencias, los números de actas con acuerdos totales o parciales y las constancias expedidas.

\section{La conciliación en la Costa Atlántica a partir del funcionamiento del SICAAC}

El Sistema de Información de la Conciliación, el Arbitraje y la Amigable Composición (SICAAC) entró en funcionamiento el día 10 de enero de 2016, siendo implementado por la resolución 018 de enero de 2016, emanada del Ministerio de Justicia y del Derecho (2016) ${ }^{1}$.

1 Minjusticia en respuesta a derecho de petición OFI17-0020288-DMA-2100 
Gracias a este sistema es posible consultar al Ministerio de Justicia con respecto al comportamiento de las solicitudes de conciliación a nivel nacional, incluyendo la Costa Atlántica, por supuesto, y de manera especial, la ciudad de Barranquilla; por consiguiente y en respuesta a derecho de petición incoado para fines de la presente investigación, se obtuvieron datos provenientes de los centros de conciliación vigentes de todo el país, así como de las solicitudes de conciliación, desde la fecha 01 de enero de 2016 hasta el 07 de julio de 2017, los cuales se analizan a continuación:

Tabla 1

Centros de conciliación acreditados en las principales ciudades de la Costa Atlántica. Enero 2016 - julio 2017

\begin{tabular}{lcc}
\hline \multicolumn{1}{c}{ Ciudad } & $\begin{array}{c}\text { Número de centros } \\
\text { de conciliación }\end{array}$ & \% del total \\
\hline Barranquilla & 19 & $32,76 \%$ \\
Cartagena & 12 & $20,69 \%$ \\
de Indias & 7 & $12,07 \%$ \\
Montería & 6 & $10,34 \%$ \\
Santa Marta & 5 & $8,62 \%$ \\
Valledupar & 4 & $6,90 \%$ \\
Sincelejo & 1 & $1,72 \%$ \\
Magangué & 1 & $1,72 \%$ \\
Valencia & 1 & $1,72 \%$ \\
Aguachica & 1 & $1,72 \%$ \\
San Juan del Cesar & 1 & $1,72 \%$ \\
Riohacha & $\mathbf{5 8}$ & $\mathbf{1 0 0 , 0 0 \%}$ \\
\hline \multicolumn{1}{c}{ Total } & & \\
\hline
\end{tabular}

Fuente: elaboración propia a partir de información del Minjusticia (2017). 
Revisadas las ciudades donde se encuentran acreditados los centros de conciliación, Barranquilla ocupa el primer lugar en la Costa Atlántica colombiana al poseer 19 centros de conciliación acreditados, lo cual equivale al 32,76 \% del total de estos centros en la Costa Atlántica. Le sigue en segundo lugar la ciudad de Cartagena con 12 centros acreditados, lo cual equivale al $20,69 \%$.

Tabla 2

Centros de conciliación acreditados en los departamentos de la Costa Atlántica. Enero 2016 - julio 2017

\begin{tabular}{lcc}
\hline \multicolumn{1}{c}{ Departamento } & $\begin{array}{c}\text { Número de centros } \\
\text { de conciliación }\end{array}$ & \% del total \\
\hline Atlántico & 19 & $32,76 \%$ \\
Bolívar & 13 & $22,41 \%$ \\
Córdoba & 8 & $13,79 \%$ \\
Magdalena & 6 & $10,34 \%$ \\
Cesar & 6 & $10,34 \%$ \\
Sucre & 4 & $6,90 \%$ \\
La Guajira & 2 & $3,45 \%$ \\
\hline \multicolumn{1}{c}{ Total } & $\mathbf{5 8}$ & $\mathbf{1 0 0 , 0 0 \%}$ \\
\hline
\end{tabular}

Fuente: elaboración propia a partir de información del Minjusticia (2017).

A nivel departamental, el departamento del Atlántico tiene el primer lugar con los mismos 19 centros de conciliación operantes en la ciudad de Barranquilla, lo que equivale al 32,76\%, y el departamento de Bolívar continúa con el segundo lugar, aumentando en uno los centros de conciliación respecto de la ciudad de Cartagena, esto es, un total de 13 centros de conciliación acreditados, lo que corresponde al $22,41 \%$. 
Tabla 3

Número de conciliaciones solicitadas y logradas total - parcial. Enero 2016 - julio 2017

\begin{tabular}{|c|c|c|c|}
\hline $\begin{array}{c}\text { Área } \\
\text { territorial }\end{array}$ & $\begin{array}{l}\text { Solicitudes de } \\
\text { conciliación }\end{array}$ & $\begin{array}{c}\text { Acuerdos } \\
\text { conciliatorios } \\
\text { totales }\end{array}$ & $\begin{array}{c}\text { Acuerdos } \\
\text { conciliatorios } \\
\text { parciales }\end{array}$ \\
\hline $\begin{array}{l}\text { Total } \\
\text { nacional }\end{array}$ & 145621 & 52762 & 1821 \\
\hline $\begin{array}{l}\text { Costa } \\
\text { Atlántica }\end{array}$ & 11971 & 5017 & 69 \\
\hline Barranquilla & 5354 & 2292 & 22 \\
\hline
\end{tabular}

Fuente: elaboración propia a partir de información del Minjusticia (2017).

Durante un período de 18 meses aproximados, de los que derivó la información emanada del Ministerio de Justicia, conforme al número de solicitudes presentadas a nivel nacional, se concluye que, de las 145.621 solicitudes presentadas, la Costa Atlántica contribuyó en un 8,22 \% del total nacional, y que la ciudad de Barranquilla tuvo una participación del $3,67 \%$ de ese mismo total nacional, y no menos relevante, un $44 \%$ respecto de la Costa Atlántica. Del mismo informe se infiere que la Costa Atlántica aporta al consolidado nacional, respecto de las conciliaciones totales nacionales, un 9,5\%, y la ciudad de Barranquilla, un 4,3\%, no dejando de lado que Barranquilla, respecto del total de la Costa Atlántica, participa en un $45,68 \%$.

En conciliaciones parciales, la Costa Atlántica posee un $3,78 \%$ del total nacional y la ciudad de Barranquilla un 1,2\%. Si se considera la participación de la ciudad de Barranquilla versus la participación total de la Costa Atlántica, la ciudad contribuye en un 31,88\%.

Por último, es de resaltar que, conforme a los datos estudiados, a nivel nacional, de las solicitudes presentadas, el $37,48 \%$ se materializa en conciliaciones totales o parciales 
de las controversias. En la Costa Atlántica (acuerdos totales o parciales) se alcanza un porcentaje del $42,48 \%$; a su vez, en la ciudad de Barranquilla, del $100 \%$ de las solicitudes, el 43,22 \% desembocan en conciliaciones totales o parciales.

Observando los resultados anteriores, la Costa Atlántica posee una participación relativamente baja a nivel nacional en materia de conciliaciones, pero si se considera a Barranquilla de forma individual, observamos su impacto positivo en la Costa Atlántica, ya sea por el número de centros de conciliación, solicitudes y acuerdos totales o parciales. El simple hecho de que del total de los acuerdos de conciliación en la Costa Atlántica, el $45 \%$ sea en la ciudad de Barranquilla, permite observar el impulso de la conciliación como mecanismo alternativo de solución de conflictos en la ciudad, en el entendido que ésta constituye una forma de acceso a la justicia que evita una mayor congestión judicial, al igual que asegura una solución pacífica de los conflictos entre las partes involucradas.

No está de más aducir que, si se impregnara aún más la conciliación en el conocimiento común de las personas, es decir, si se socializara en profundidad la utilidad de la conciliación y el fin que trae la misma, en el sentido de la oportunidad de solución pacífica de controversias, se podría prever no solo un aumento en las solicitudes de conciliación, sino también en los porcentajes de los acuerdos totales o parciales que darían fin a controversias sustanciales, y desde la perspectiva de la Costa Atlántica, aumentarían los indicadores de aquellos municipios que aún no le han dado la relevancia que se observa en la ciudad de Barranquilla.

\section{ConClusiones}

1. La conciliación como medio alternativo de solución de conflictos es una herramienta real y cierta de acceso a la justicia de manera pacífica que propicia la tutela judicial efectiva a las partes intervinientes sin necesidad de la comparecencia de un juez de la República que determine ejerciendo su poder de coerción y de decisión cómo se resuelve su controversia. 
2. La conciliación, como requisito de procedibilidad, no demerita la oportunidad a las partes para resolver su conflicto a través de una justicia autocompositiva.

3. La incidencia de la Costa Atlántica en las solicitudes de conciliación ante los centros habilitados podría ser aún mayor en la media nacional si se incentiva la creación de centros de conciliación, además, es preponderante la socialización, con el ciudadano, de la relevancia que implica el acceso a este mecanismo autocompositivo, pretendiendo con esto que se deje de considerar a la acción judicial como la primera opción de la solución de litis y se interiorice y prevalezca la conciliación como primer gran escenario de solución pacífica de controversias.

4. Es importante el aporte que hace la ciudad de Barranquilla, tanto a nivel nacional como en la Costa Atlántica, con respecto a centros de conciliación habilitados y en acuerdos totales o parciales derivados del mismo proceso conciliatorio; no obstante, se puede observar la necesidad de adelantar mayores esfuerzos para aumentar los indicadores de acceso a los centros de conciliación.

5. Considerar la materialización de campañas de socialización, interiorización y conocimiento del mecanismo de la conciliación para los habitantes del territorio nacional que hagan hincapié en las bondades de la conciliación como método alternativo de solución de conflicto, no solo para aumentar los resultados que reflejan el final de los conflictos ante en SICAAC, sino además, con el fin de concientizar sobre la oportunidad que existe de solucionar de manera pronta, oportuna y sin mayores desgastes los asuntos objeto de discusión entre las partes. La conciliación debe convertirse en una prioridad, tanto en el ciudadano como en la educación media vocacional, para que nuevas generaciones interioricen la importancia de ella como la primera oportunidad cierta de solución pacífica de controversias. 


\section{REFERENCIAS}

Arboleda, D., Ramírez, C., Mancipe, G. Garcés, L. y Arboleda, S. (2018). La conciliación virtual extrajudicial en Derecho; reflexiones frente a la ética. Justicia, 24(34), 372-384. https:// doi.org/10.17081/just.23.34.2897

Arrieta, M. y Rojas, A. (2002). Análisis de las garantías del proceso de alimentos y su eficacia dentro del proceso. [Tesis]. Universidad del Norte, Barranquilla, Colombia.

Azula, J. (2016). Manual de derecho procesal. Tomo I. Bogotá, D.C.: Temis.

Bermejo, J. (2015). La Conciliación Prejudicial Contenciosa Administrativa. Jurídicas CUC, 11(1), 101-124. http://dx.doi. org/10.17981/juridcuc.11.1.2015.5

Castillo, C. (2012). La conciliación extrajudicial y la necesidad de su rango constitucional. Pontificia Universidad Católica del Perú. Recuperado de http://blog.pucp.edu.pe/blog/conciliacionyarbitrajepatmos/2012/03/06/la-conciliacion-extrajudicialy-la-necesidad-de-su-rango-constitucional/

Cuesta-Cuesta, D. (2015). La conciliación en el ordenamiento jurídico colombiano. Una nueva forma de enseñar Derecho. Bogotá, D.C.: Ediciones Universidad Cooperativa de Colombia. https://doi.org/10.16925/greylit.1443

González, R. (1999). Exposición de motivos Ley 640 de 2001. Ministro de Justicia y del Derecho, Senado de la Republica y Secretaria general Senado de la República. Recuperado de http://www.alcaldiabogota.gov.co/sisjurMantenimiento/normas/Norma1.jsp?i=7380

Maldonado, M. y Montaña, L. (2017). Arbitraje: mecanismo alternativo de solución de conflictos o privatización judicial. Jurídicas CUC, 13(1), 121-146. http://dx.doi.org/10.17981/ juridcuc.13.1.2017.6

Pallares, J. (2003). Arbitraje, conciliación y resolución de conflictos. Bogotá, D.C.: Leyer. 
República de Colombia. Congreso de la República de Colombia. (7 de julio de 1998). Por la cual se adoptan como legislación permanente algunas normas del Decreto 2651 de 1991, se modifican algunas del Código de Procedimiento Civil, se derogan otras de la Ley 23 de 1991 y del Decreto 2279 de 1989, se modifican y expiden normas del Código Contencioso Administrativo y se dictan otras disposiciones sobre descongestión, eficiencia y acceso a la justicia. [Ley 446 de 1998]. DO: 43.335.

República de Colombia. Congreso de la República de Colombia. (5 de enero de 2001). Por la cual se modifican normas relativas a la conciliación y se dictan otras disposiciones. [Ley 640 de 2001]. DO: 44.303.

República de Colombia. Congreso de la República de Colombia. (8 de enero de 2003). Por la cual se modifica el Código de Procedimiento Civil, se regula el proceso ejecutivo y se dictan otras disposiciones. [Ley 794 de 2003]. DO: 45058.

República de Colombia. Congreso de la República de Colombia. (12 de julio de 2012). Por medio de la cual se expide el Código General del Proceso y se dictan otras disposiciones. [Ley 1564 de 2012]. DO: 48489.

República de Colombia. Corte Constitucional, Sala plena. (15 de noviembre de 2001). Sentencia C-1195. Exp. D-3519. [MP Manuel José Cepeda Espinoza y Marco Gerardo Monroy Cabra].

República de Colombia. Corte Constitucional. Sala plena. (22 de agosto de 2001). Sentencia C-893. Exp: D-3399. [MP Clara Inés Vargas Hernández].

República de Colombia. Corte Constitucional. Sala plena. (30 de abril de 2002). Sentencia C-314. Exp. D-3638. [MP Marco Gerardo Monroy Cabra].

República de Colombia. Asamblea Nacional Constituyente. (1991). Constitución Política de Colombia. [Const]. Recuperado de http://www.suin-juriscol.gov.co/viewDocument. asp?ruta=Constitucion $/ 1687988$

República de Colombia. Ministerio de Justicia y del Derecho. (9 de junio de 2017). Por el cual se adiciona el Capítulo 13 al Título 3 de la Parte 2 del Libro 2 del Decreto 1069 de 2015, Decreto Único Reglamentario del Sector Justicia y se adopta el Plan Decenal del Sistema de Justicia 2017-2027. [Decreto 979]. DO: 50259. 
República de Colombia. Ministerio del Trabajo de Colombia. (2018). Efectos de la audiencia de conciliación celebrada ante el Ministerio de Trabajo. [Concepto técnico 3970 de 2018]. Radicado 08SE2018120300000007387. Recuperado de http:// www.mintrabajo.gov.co/web/guest/relaciones-laborales/comision-permanente-de-concertacion/-/document_library/hd6QKB3cs5p9/view_file/58998686

República de Colombia. Ministerio de Justicia y del Derecho. (20 de enero de 2016). Por la cual se adopta el Sistema de Información de la Conciliación, el Arbitraje y la Amigable Composición (SICAAC). [Resolución 18]. DO: 49.761. Recuperado de http://www.minjusticia.gov.co/Portals/0/Normatividad1/ActosAdministrativos/Resoluciones/2016/Resoluci\%C3\%B3n\%20 0018\%20del\%2018\%20de\%20enero\%20de\%202016.pdf

República de Colombia. Presidencia de la República de Colombia. (7 de octubre de 1989). Por el cual se introducen algunas modificaciones al Código de Procedimiento Civil. [Decreto 2282]. DO: 39013 .

Rojas, M. (2013). Lecciones de Derecho Procesal. Bogotá, D.C: ESAJU.

Tamayo, A. (2004). Manual de obligaciones. Bogotá, D.C.: Temis.

Tamez, G., Montalvo, D., Leyva, O. y Hernández, A. (2018). Análisis comparativo sobre los métodos alternativos para la resolución de conflictos a partir de la legislación de los Estados de la República Mexicana. Justicia, 24(34), 385-404. https:// doi.org/10.17081/just.23.34.2899 
Abel Meza Godoy es Abogado (2003). Especialista en Derecho Económico (2011). Magíster en Dirección y Administración de Empresas (2016). Profesor de Derecho Procesal Civil del Departamento de Derecho y Ciencias Políticas de la Universidad de la Costa CUC de Barranquilla.

Milton Arrieta López es Abogado (2002). Especialista en Derecho Económico (2011). Magíster en Dirección y Administración de Empresas (2016). Maestrando en Derechos Humanos, Democracia y Globalización. Profesor de Derecho Privado del Departamento de Derecho y Ciencias Políticas de la Universidad de la Costa CUC de Barranquilla.

Sara Noli es Politóloga (2004). Magíster DITALS (2016). Profesora de Lengua y cultura italiana de la Universidad del Norte de Barranquilla. 